\title{
Adenosine as a metabolic regulator of tissue function: production of adenosine by cytoplasmic 5'-nucleotidases
}

\author{
Agnieszka Borowiec, Katarzyna Lechward ${ }^{1}$, Kinga Tkacz-Stachowska ${ }^{2}$ \\ and Andrzej C. Składanowski ${ }^{凶}$ \\ Department of Molecular Enzymology, Intercollegiate Faculty of Biotechnology UG-MUG, Medical University

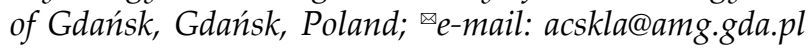

Received: 25 April, 2006; revised: 17 May, 2006; accepted: 25 May, 2006 available on-line: 12 June, 2006

\begin{abstract}
Adenosine is a product of complete dephosphorylation of adenine nucleotides which takes place in various compartments of the cell. This nucleoside is a significant signal molecule engaged in regulation of physiology and modulation of the function of numerous cell types (i.e. neurons, platelets, neutrophils, mast cells and smooth muscle cells in bronchi and vasculature, myocytes etc.). As part a of purinergic signaling system, adenosine mediates neurotransmission, conduction, secretion, vasodilation, proliferation and cell death. Most of the effects of adenosine help to protect cells and tissues during stress conditions such as ischemia or anoxia. Adenosine receptors and nucleoside transporters are targets for potential drugs in many pathophysiological situations. The adenosine-producing system in vertebrates involves a cascade dephosphorylating ATP and ending with $5^{\prime}$-nucleotidase (EC 3.1.3.5) localized either on the membrane or inside the cell. In this paper the cytoplasmic variants of $5^{\prime}$-nucleotidase are broadly characterized as well as their clinical relevance. The role of AMP-selective 5'-nucleotidase (cN-I) in the heart, skeletal muscle and brain is highlighted. cN-I action is crucial during ischemia and important for the efficacy of some nucleoside-based drugs and in the regulation of the substrate pool for nucleic acids synthesis. Inhibitors used in studying the roles of cytoplasmic and membrane-bound $5^{\prime}$-nucleotidases are also described.
\end{abstract}

Keywords: adenosine, 5'-nucleotidase, metabolic regulation

\section{ADENOSINE - A REGULATORY NUCLEOSIDE}

Adenosine (Ado) is a signaling molecule working in an autocrine or paracrine way. The potent effect of adenylic compounds in the heart and blood vessels was first described by Drury and Szent-Györgi in 1929. The large amounts of adenosine produced by a cascade hydrolysis of ATP can affect the homeostasis of high-energy compounds inside the cell in a feed-back way. This was the reason to name adenosine "a retaliatory metabolite" that is able to counteract the action of the enzymes raising
cAMP level and triggering an energy burst. In such a way adenosine plays an important role in balancing energy supply with demand in the tissues where the energy output is high (Newby, 1984; Downey \& Forman, 1993).

The metabolism of adenosine is illustrated in Fig. 1. This metabolite is generated mainly by two enzymatic systems: intra- $(\mathrm{cN}-\mathrm{I})$ or extracellularly localized 5'-nucleotidases (e5'-NT) and cytoplasmic $S$-adenosylhomocysteine hydrolase (SAHH; hydrolysis of SAH is associated with transmethylation reactions). The processes of adenosine elimination in the

${ }^{1}$ Present address: Department of Medical Biochemistry, Medical University Vienna, Vienna, Austria.

${ }^{2}$ Present address: Department of Pathology, Norwegian Radium Hospital, Oslo, Norway.

Abbreviations: ADA, adenosine deaminase; AK, adenosine kinase; AMPDA, AMP deaminase; AOPCP, $\alpha, \beta$-methyleneadenosine 5'-diphosphate; cAMP, cyclic 3',5'-adenosine monophosphate; cN-I, cytoplasmic 5'-nucleotidase-I (AMP-selective); cN-II, cytoplasmic 5'-nucleotidase II (IMP-selective or GMP/IMP-selective); cN-III, cytoplasmic 5'-nucleotidase III; $\mathrm{CNS}$, central nervous system; dCK, deoxycytidine kinase; e5'-NT, ecto-5'-nucleotidase; mNT, mitochondrial nucleotidase; MT, methyltransferase; 5'-NT, 5'-nucleotidase (general); PLA2, phospholipase A2; PLC, phospholipase C; PLD, phospholipase D; PNP, purine nucleoside phosphorylase; $\mathrm{SAHH}$, S-adenosylhomocysteine hydrolase; XO, xanthine oxidase. 


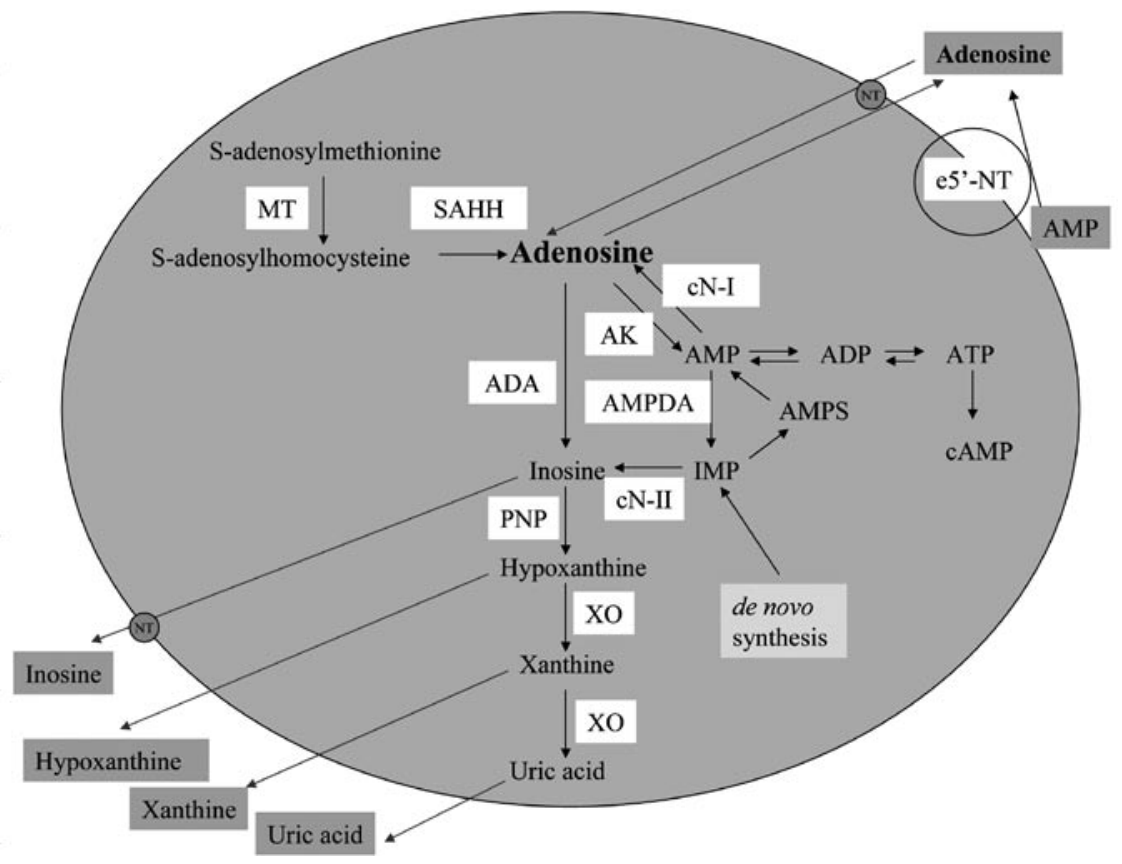

Figure 1. Adenosine metabolism in the cell.

cN-I, cytoplasmic 5'-nucleotidase-I (AMP selective); cN-II, cytoplasmic 5'-nucleotidase-II (IMP selective or IMP/GMP selective); ADA, adenosine deaminase; AK, adenosine kinase; AMPDA, AMP deaminase; e5'-NT, ecto-5'-nucleotidase; MT, methyltransferase; NT, nucleoside transporter; PNP, purine nucleoside phosphorylase; SAHH, S-adenosylhomocysteine hydrolase; $\mathrm{XO}$, xanthine oxidase.

cell involve reactions catalyzed by adenosine deaminase and adenosine kinase (Shryock \& Belardinelli, 1997) yielding inosine or 5'-AMP, respectively. The reaction of phosphorylation predominates when adenosine occurs at a low physiological concentration $(<1 \mu \mathrm{M})$ whereas adenosine deaminase is activated at higher concentrations of the substrate $(>10 \mu \mathrm{M})$. Purine nucleoside phosphorylase has only a negligible activity towards adenosine and degrades mainly inosine and guanosine. Some cells may carry out purine conversion down to uric acid as the ultimate product, others release less oxidized purines.

5'-Nucleotidases (EC 3.1.3.6) have a regulatory impact on purine metabolism and can influence the cellular level of (deoxy)adenylates and other nucleotides. Dephosphorylation of different nucleoside monophosphates is performed by distinct isoforms although they are generally only regiospecific towards the $5^{\prime}$-position in ribose or deoxyribose. Seven mammalian 5'-nucleotidases have been cloned until now (for a review see Bianchi \& Spychala, 2003). Four isoforms are ubiquitous (eN, cN-II, cdN, mdN) whereas the others display more tissue-specific expression (cN-IA, cN-IB, cN-III).

The physiological effect of adenosine is mediated via specific receptors. They are classified as purinergic P1-type and situated in the plasma membrane. These $G$ protein-coupled receptors have seven trans-membrane protein domains. Up to now four types of adenosine receptors $\left(\mathrm{A}_{1}, \mathrm{~A}_{2 \mathrm{~A}^{\prime}} \mathrm{A}_{2 \mathrm{~B}}\right.$ and $\left.\mathrm{A}_{3}\right)$ have been recognized and cloned from many mam- malian and non-mammalian species (for a recent review see Yaar et al., 2005). The subclassification of adenosine receptors is based on the effects which they cause over changing cAMP concentration in the cell and their affinity for the ligand (see Table 1). Within any particular subtype, the receptors from various mammalian tissues are highly similar to each other. Adenosine is their only endogenous agonist, however, $\mathrm{A}_{3}$ receptor can be activated also by inosine (Fredholm et al., 2001). The distribution of the subtypes varies greatly. For example, those localized in the heart are classified as $\mathrm{A}_{1}$ (present only on atrial cells), $\mathrm{A}_{2 \mathrm{~A}}$ (of intermediate abundance) and $\mathrm{A}_{3}$ (of low abundance) (Fredholm et al., 2000). The $\mathrm{A}_{1}$, $A_{2 A^{-}}$and $A_{2 B}$-type receptors are present on skeletal muscle filaments (Fredholm et al., 2000; Radegran \& Hellsten, 2000). The genomic structure appears to be similar for all human adenosine receptor genes and all four types are asparagine-linked glycoproteins (Fredholm et al., 2000). The $\mathrm{A}_{2 \mathrm{~A}}$ - and $\mathrm{A}_{2 \mathrm{~B}}$-type preferably interact with the $G_{s}$ protein and the $A_{1}$ - and $\mathrm{A}_{3}$-type act via the $\mathrm{G}_{\mathrm{i} / \mathrm{o}}$ protein.

Adenosine exerts diverse physiological effects in various tissues (Imai \& Nakazawa, 1991). The effects vary greatly depending on the population of the receptor subtype in the particular tissue (Table 2). Generally, this nucleoside is an inhibitory signaling molecule. It protects the myocardial and cerebrovascular systems against ischemia-induced damage (Ely \& Berne, 1992; Obata, 2002) by slowing cardiac output. It also limits the degree of vascular 
Table 1. Distribution of adenosine receptors and effects of their activation (from Fredholm et al., 2000)

\begin{tabular}{|c|c|c|c|c|}
\hline Type & $\mathrm{A}_{1}$ & $\mathrm{~A}_{2 \mathrm{~A}}$ (low affinity) & $\mathrm{A}_{2 \mathrm{~B}}$ (high affinity) & $\mathrm{A}_{3}$ \\
\hline Species of cloning & $\begin{array}{l}\text { man, rat, mouse, dog, } \\
\text { cow, rabbit, guinea } \\
\text { pig, chicken }\end{array}$ & man, rat, mouse, dog, guinea pig & $\begin{array}{l}\text { man, rat, mouse, } \\
\text { chicken }\end{array}$ & $\begin{array}{l}\text { man, rat, mouse, } \\
\text { dog, sheep, } \\
\text { chicken }\end{array}$ \\
\hline $\begin{array}{l}\text { Organs with high } \\
\text { expression }\end{array}$ & $\begin{array}{l}\text { brain, spinal cord, eye, } \\
\text { adrenal gland, atria }\end{array}$ & $\begin{array}{l}\text { spleen, thymus, leukocytes, blood } \\
\text { platelets, striatopallidal GABA-ner- } \\
\text { gic neurons, olfactory bulb }\end{array}$ & $\begin{array}{l}\text { caecum, colon, } \\
\text { bladder }\end{array}$ & $\begin{array}{l}\text { testis (rat), mast } \\
\text { cells (rat) }\end{array}$ \\
\hline $\begin{array}{l}\text { Effects of G-protein } \\
\text { coupling }\end{array}$ & $\begin{array}{l}\downarrow \text { cAMP } \\
\uparrow \mathrm{IP}_{3} / \mathrm{DAG}(\mathrm{PLC}) \\
\uparrow \text { arachidonate }\left(\mathrm{PLA}_{2}\right) \\
\uparrow \text { choline (PLD) }\end{array}$ & $\begin{array}{l}\uparrow \mathrm{cAMP} \\
\uparrow \mathrm{IP}_{3}\end{array}$ & $\begin{array}{l}\uparrow c A M P \\
\uparrow \mathrm{IP}_{3} / \mathrm{DAG}(\mathrm{PLC})\end{array}$ & $\begin{array}{l}\downarrow \text { cAMP } \\
\uparrow \mathrm{IP}_{3} / \mathrm{DAG} \\
(\mathrm{PLC})\end{array}$ \\
\hline
\end{tabular}

Explanation: $\downarrow$, decrease; and $\uparrow$, increase of concentration.

injury after ischemia and reperfusion by reducing reactive oxygen species release and inhibiting platelet aggregation (Ely \& Berne, 1992). Adenosine is implicated in neuromodulatory (Dunwiddie \& Haas, 1985; Lu et al., 2004) and anti-inflammatory mechanisms (Cronstein, 1994). It has also analgesic properties (Sawynok \& Sweeney, 1989), may influence proliferation, survival or apoptosis of many different cells (Jacobson et al., 1999) and work as a potent suppressor in the immune system (Spychala et al., 1997).

Adenosine receptors are considered as putative targets for specific drug development. The adenosine receptors-based therapy concerns Parkinson's disease, hypoxia/ischemia, epilepsy, kidney disease and asthma (Fredholm, 2003).

\section{ROLE OF ADENOSINE IN THE HEART}

The physiological function of adenosine in the cardiovascular and central nervous systems is well recognized (Berne et al., 1983). When a stress situation occurs such as ischemia, hypoxia or increased workload, the myocardial metabolism is adapted to reverse the pathological consequences (Rubio et al., 1973). If the rate of energy consumption exceeds the rate of energy production, the net breakdown of ATP results in an increased production of adenosine. Elimination of the stress takes place by restoring the balance between ATP generation and utilization. The actions exerted then are: coronary vasodilation, inhibition of the sinoatrial and atrioventricular con- duction and antagonizing adrenergic stimulation. All of them bring the myocardial oxygen supplyto-demand ratio back to normal (Ballardinelli et al., 1989).

The adenosine production in the myocardium is dependent on both cytoplasmic and extracellular 5 '-nucleotidases. However, only cN-I is the isoform that is sensitive to the level of energy compounds inside the cell. Decrease of ATP and increase of ADP is a primary stimulus for $\mathrm{cN}-\mathrm{I}$ to work (Skladanowski \& Newby, 1990; Darvish et al., 1996). Adenosine circulating in coronary vessels originates both from myocytes (Rubio et al., 1973) and endothelial cells (Deussen et al., 1986). This has led to a theory that not only myocardial but also endothelially-produced adenosine has a protective role.

\section{ROLE OF ADENOSINE IN NERVOUS SYSTEM}

As mentioned in Table 2 adenosine is a neuronal signaling substance which plays a significant role in the central and peripheral nervous systems (Zimmermann, 1994). In CNS adenosine targets are neurons, glia and cerebral blood vessels; in the periphery it regulates neurons, muscles and endothelial cells. Adenosine can modulate neural functions in many ways. It inhibits the release of most transmitters via $\mathrm{A}_{1}$ receptors, presumably by inhibition of presynaptic $\mathrm{Ca}^{2+}$-channels. The neuroprotective role of adenosine concerns also the control of the release of ATP from purinergic neurons. Adenosine may play a specific role in the development and regener-

Table 2. Summary of physiological effects of the activation of adenosine receptors (according to Relavic \& Burnstock, 1998)

\begin{tabular}{ll}
\hline $\mathrm{A}_{1}$ & $\begin{array}{l}\text { Inhibition of neurotransmission; negative chronotropy, dromotropy and inotropy; up-regulation of insulin secretion } \\
\text { and control of lipolysis; ischemic preconditioning of heart; modulation of nociception }\end{array}$ \\
\hline $\mathrm{A}_{2 \mathrm{~A}}$ & $\begin{array}{l}\text { Facilitation of neurotransmitter release; negative interaction with } \mathrm{A}_{1} \text { and } \mathrm{A}_{3} \text { types and other receptors; vasodila- } \\
\text { tion of capillary blood vessels; stimulation of growth of endothelial cells and angiogenesis }\end{array}$ \\
\hline $\mathrm{A}_{2 \mathrm{~B}}$ & $\begin{array}{l}\text { Degranulation of mastocytoma cells; possible role in allergic and inflammatory disorders; vasodilation of capillary } \\
\text { blood vessels; possible tropic role in release of other signaling substances }\end{array}$ \\
\hline $\mathrm{A}_{3}$ & Possible role in inflammation; proapoptotic effects; cardioprotective effects (the same as $\mathrm{A}_{1}$ ) \\
\hline
\end{tabular}


ation of the nervous system (Zimmermann \& Braun, 1996). In the salvage system, adenosine may serve as a substrate for restoration of adenylates after reuptake via nucleoside transporters (Thorn \& Jarvis, 1996).

\section{ROLE OF ADENOSINE IN THE SKELETAL MUSCLE}

The role of adenosine in the skeletal muscle is less well elucidated. As a vasoactive substance, it is a candidate regulatory compound of blood flow (Radegran \& Hellsten, 2000). A more important role probably concerns the connections between muscle and nerves. Adenosine-induced apoptosis may represent a pathogenic pathway in muscular dystrophy (Jacobson et al., 1999). Adenosine exerts effects in both neuromuscular junctions and contractile myofibrils. It is known that adenosine derived from newly released ATP by cascadic degradation is the cause of skeletal neuromuscular depression (Silinsky, 1975). In a negative feedback the secretion of acetylcholine and ATP is inhibited by extracellularly produced adenosine.

Adenosine takes part in regulation of energy metabolism of a working muscle. Two functional proteins: tropomyosin- and troponin-complex, present in thin filaments, regulate the process of contraction. The allosteric mechanism of this control is dependent on $\mathrm{Ca}^{2+}$ concentration. A nervous impulse causes an increase of cytoplasmic calcium. Following that, $\mathrm{Ca}^{2+}$ binds to troponin and induces conformational changes of the muscle proteins that allow contraction to occur. The release of adenosine has been found to parallel the cytoplasmic $\mathrm{Ca}^{2+}$ pulse in the contracting animal muscle. Also adenosine formed outside the cell was elevated in electrically stimulated mammalian skeletal muscle cells (Hellsten, 1999). The role of adenosine in the skeletal muscle can be regarded from various aspects. The most important are the physiological regulation of blood flow in capillary vessels surrounding muscle bundles and the metabolic control of glucose utilization as a fuel (Dobson et al., 1971; Han et al., 1998). It has been found that adenosine may accumulate in the muscle tissue and unchanged can be released during contraction (Ballard, 1991; Radegran \& Hellsten, 2000). Its sources might be the contracting myocytes, vascular endothelial cells or nerve endings (Radegran \& Hellsten, 2000).

Adenosine is an autocrine or paracrine regulator in skeletal muscles as well as in the heart. In the myocytic plasma membrane, two types of adenosine receptors $\left(\mathrm{A}_{2 \mathrm{~A}}\right.$ and $\left.\mathrm{A}_{2 \mathrm{~B}}\right)$ are present. Three receptors $\left(A_{1}, A_{2 A}\right.$ and $\left.A_{2 B}\right)$ are found on vascular endothelial and smooth muscle cells (Radegran \&
Hellsten, 2000). Adenosine is known to be released from endothelial cells during systemic hypoxia and then stimulates $\mathrm{A}_{1}$ receptors (Bryan \& Marshall, 1999a). Hypoxia-induced vasodilation is initiated by stimulation of $\mathrm{A}_{1}$ receptor followed by $\mathrm{K}_{\mathrm{ATP}}$-channel opening and evoking the synthesis of nitric oxide (Bryan \& Marshall, 1999b). Hellsten and Frandsen (1997) confirmed that adenosine is released from the skeletal muscle mainly under conditions of an insufficient oxygen supply. The decrease of oxygen level in the working muscle however do not affect the rate of adenosine production (Ballard, 1991; Cheng et al., 2000). The adenosine efflux can be rather stimulated by decrease of intracellular $\mathrm{pH}$, resulted from lactate accumulation during hypoxic exercise. This is driven mainly by increased extracellular AMP concentration and an increased affinity of membrane-bound e5'NT for AMP (Cheng et al., 2000). It was observed in that paper, that putative cytoplasmic 5'-nucleotidase in the skeletal muscle has too low an activity for effective dephosphorylation of AMP at a micromolar concentration.

Despite that, it seems that the amount of adenosine in the contracting muscle cannot be supplied only by ecto-5'-nucleotidase (Rubio et al., 1973). A recent report confirmed the existence of a cytoplasmic AMP-specific form of 5'-nucleotidase (cN-I) closely resembling the heart isoform. The purified enzyme processed AMP at a submillimolar concentration and was allosterically activated by ADP. This observation gives more credibility to the role of intracellularly formed adenosine in physiological regulation of skeletal muscle function (Tkacz-Stachowska et al., 2005).

\section{ROLE OF ADENOSINE IN TUMOR PROMOTION}

Some of the adenosine functions have recently been implicated in the promotion of tumorigenesis. It acts as a very potent cytoprotective and immunosuppressive agent and also has an ability to inhibit cytokine synthesis and adhesion of cells to the endothelium as well as to influence the function of lymphocytes $\mathrm{T}$, macrophages and natural killer cells. Moreover, adenosine takes part in cell induction and proliferation, also in relation to cancer cells (Spychala, 2000). However, more results are needed to verify this new aspect of adenosine as a signaling molecule.

\section{THE FAMILY OF 5'-NUCLEOTIDASES}

5'-Nucleotidases hydrolyze non-cyclic nucleoside monophosphates or deoxynucleoside monophosphates to (deoxy)nucleosides and inorganic 
phosphate. Some variants can transfer inorganic phosphate from a nucleoside monophosphate onto another nucleoside. The group of $5^{\prime}$-nucleotidases together with nucleoside kinases regulate nucleotide levels in proliferating cells (Bianchi et al., 1986). The nomenclature of $5^{\prime}$-NTs is based mainly on their subcellular compartmentation. Five are localized in the cytosol, one is in the mitochondrial matrix and one is attached to the outer side of the plasma membrane. All cytoplasmic forms are $\mathrm{Mg}^{2+}$-dependent. They vary in substrate specificity, molecular and kinetic properties. Their common feature is subunit complexity and allosteric regulation. The enzymes are filogenetically distant and there are no significant similarities between the primary structures of these proteins. For details see the recent review by Bianchi and Spychala (2003).

\section{DIFFERENT ROLES OF CYTOPLASMIC $5^{\prime}$ - NUCLEOTIDASES IN TISSUE-SPECIFIC METABOLISM}

\section{cN-I}

$5^{\prime}$-Nucleotidase-I is highly expressed in skeletal and heart muscles (Sala-Newby et al., 1999; SalaNewby et al., 2000). Until now $\mathrm{cN}-\mathrm{I}$ has been purified and characterized from the heart of many species including rabbit (Yamazaki et al., 1991), pigeon (Sala-Newby et al., 2000), rat (Truong et al., 1988), dog (Darvish \& Metting, 1993), and man (Skladanowski et al., 1996). cN-I has been cloned from pigeon (Sala-Newby et al., 2000), mouse (Sala-Newby \& Newby, 2001) and human (Hunsucker et al., 2001). Heart is the richest source of $\mathrm{cN}-\mathrm{I}$ in pigeon but this form is also abundant in the brain and breast muscle. In human tissues, there are two genes (NT5C1A and $N T 5 C 1 B$ ) giving closely related products $-\mathrm{CN}$ IA and $\mathrm{cN}-\mathrm{IB}$, respectively. cN-IA mRNA expression is highest in skeletal and heart muscle, a moderate level of the enzyme appears in the pancreas and brain and a low level is present in the kidney, testes and uterus (Hunsucker et al., 2001).

Cytoplasmic 5'-nucleotidase-I has a high affinity for both nucleoside and deoxynucleoside monophosphates (see Table 3). The latter, however, are converted with a much lower rate. The preferred substrate for $\mathrm{CN}-\mathrm{I}$ is AMP but also various pyrimidine deoxyribonucleoside monophosphates (Garvey et al., 1998; Hunsucker et al., 2001; Tkacz-Stachowska et al., 2005). The $K_{\mathrm{m}}$ for AMP in partially purified human heart enzyme was $1.46 \mathrm{mM}$ (Skladanowski et al., 1996), similarly to the purified recombinant human heart enzyme where it was $1.9 \mathrm{mM}$ (Hunsucker et al., 2001).
cN-I is strongly activated by ADP (Skladanowski \& Newby, 1990). Depending on the substrate concentration and the source of enzyme, halfmaximal activation of cN-I appears to vary between 10 and $89 \mu \mathrm{M}$ ADP (Skladanowski \& Newby, 1990; Yamazaki et al., 1991; Garvey et al., 1998; Hunsucker et al., 2001). The impulse from ADP increase seems to be the main trigger to activate cN-I. To a lesser degree the enzyme is activated by GTP (Hunsucker et al., 2001). The activity of cN-I is influenced by $\mathrm{pH}$ (Newby, 1988; Yamazaki et al., 1991; Skladanowski et al., 1996) and different divalent cations: $\mathrm{Mg}^{2+}, \mathrm{Mn}^{2+}$ and $\mathrm{Co}^{2+}$ (Skladanowski \& Newby, 1990; Yamazaki et al., 1991; Darvish \& Metting, 1993; Skladanowski et al., 1996). A selective inhibitor of cN-I is 5-ethynyldideoxyuridine (5-EddU) (Garvey et al., 1998). An acknowledged role of the enzyme in humans is delivering adenosine during ischemic or hypoxic condition. This is crucial for prevention of heart damage (Cross et al., 2002). Also its role in modulation of the pharmacological effects of nucleoside-based drugs is considered (Hunsucker et al., 2005).

Murine cN-I has been cloned from the heart and testes (Sala-Newby \& Newby, 2001). It appeared then that the enzyme was a product of a distinct gene. The sequence was closely related to human $\mathrm{cN}-\mathrm{IB}$ but not to $\mathrm{cN}-\mathrm{IA}$. Among highly homologous genes one worth noting is a gene that encodes putative human autoimmune infertility protein (AIRP) but the exact relation of both genes calls further investigations. Human $\mathrm{CN}-\mathrm{IB}$ is highly expressed in testes; the lowest level of expression estimated by RT-PCR analysis was observed in the brain and skeletal muscle. Full substrate specificity pattern of $\mathrm{cN}$ IB is still unknown, but the initial enzyme characteristic appears similar to that of cN-IA. Overexpression of cloned murine cN-IB in COS-7 cells showed that the enzyme preferably hydrolyzes AMP and is allosterically activated by ADP, both characteristic also to cN-IA (Sala-Newby \& Newby, 2001).

\section{cN-II}

Cytoplasmic 5'-nucleotidase-II (cN-II) is also known as high- $K_{\mathrm{m}} 5^{\prime}$-NT, purine $5^{\prime}$-NT or IMP/GMP selective $5^{\prime}$-NT. It is a 6-hydroxypurine nucleoside monophosphate-specific enzyme (Itoh, 1993; see also Table 3). It is not involved in the regulation of the deoxyribonucleotide pool but affects IMP and GTP concentration (Gazziola et al., 2001). cN-II has a phosphotransferase activity and the formation of a covalently-bound phosphoenzyme intermediate has been found (Allegrini et al., 2001). The phosphate transfer onto a purine nucleoside acceptor is dependent on the local concentration of nucleosides. In its absence, the phosphate moiety is removed by hydrolysis. Under physiological conditions, the phos- 
phate can be transferred onto inosine and guanosine and also onto nucleoside analogs. The enzyme is widely expressed and its sequence is remarkably conserved among various vertebrates. Human cN-II was cloned in 1994 by Oka and coworkers. Highly elevated activity of a soluble 5'-nucleotidase has been associated with developmental neurological disorders and Lesh-Nyhan syndrome (Page et al., 1997; Pesi et al., 2000). Judging by its substrate preferences the enzyme should be classed as cN-II.

cN-III

Cytoplasmic 5'-nucleotidase-III (cN-III) is also known as PN-I, P5'N-1 or UMPH-1 (uridine monophosphate hydrolase-1). Its enzymatic activity (see also Table 3) is inhibited by exposition to heavy metals and thiol-reactive compounds (Amici \& Mag$\mathrm{ni}, 2002)$. The sequence of $\mathrm{cN}$-III is identical with that of another protein termed p36, an interferon $\alpha$ induced protein of unknown function (Amici et al., 2000). cN-III catalyzes dephosphorylation of pyrimidine nucleoside monophosphates to the corresponding nucleosides. It is much less active with purine nucleotides. The enzyme is highly expressed in red blood cells where it participates in the degradation of RNA during erythrocyte maturation. A cN-III deficiency is associated with inherited hemolytic anemia (Rees et al., 2003).

\section{MOLECULAR GENETICS OF ISOFORM cN-I}

The first successful cloning of a full length vertebrate 5'-nucleotidase-I was done by SalaNewby and coworkers in 1999. They utilized PCRbased screening of pigeon ventricular library with a degenerated primer derived from the peptide sequence of the heart isoform. The longest among the clones obtained encoded an open reading frame of 358 amino acids with a predicted molecular mass of $39472 \mathrm{Da}$. At that time, no homologs of the enzyme existed in the SWISS PROT database. The cloned cN-I molecule was not significantly similar to $\mathrm{cN}-\mathrm{II}$ or to e $5^{\prime}-\mathrm{NT}$. Therefore it was classified as the first member of a new family of $5^{\prime}$-nucleotidases. A detailed sequence analysis, based on a motifs prediction software tool (PSORT program) revealed a putative nuclear localization sequence (NLS) at the $\mathrm{N}$ terminus. Expression studies, carried out by Northern blotting technique, found one major transcript of approx. $2.3 \mathrm{~kb}$ in several pigeon tissues, including brain, skeletal muscle and heart. In spite of the NLS presence, when exogenously expressed in green monkey kidney cell line (COS-7), cN-I was localized to the cytoplasm, as judged by immunochemistry studies with enzyme-specific antibodies. This result was in line with the previous data obtained by electron microscopic immunogold labeling of AMPselective $5^{\prime}$-nucleotidase, as it was then named, in sections from dog heart (Darvish \& Metting, 1993). This pointed to a lack of functional consequences of NLS presence. One could speculate on another possible explanation of the observed discrepancy between the predicted and actual localization of the enzyme, involving conditional targeting of $\mathrm{cN}$ I to the nucleus upon an as yet unidentified stimulus. On the other hand, the PSORT program used in those studies distinguished three types of NLS sequence, and used the heuristic that nuclear proteins are usually enriched in basic residues which comprise more than $20 \%$ of the molecule, resulting in a prediction accuracy of $57 \%$ as estimated for yeast proteins. Until now there is no evidence in the literature that AMP-selective cytoplasmic 5 '-nucleotidase of any studied species localizes to the nucleus.

Table 3. Summary of properties of cytoplasmic 5'-nucleotidases

\begin{tabular}{|c|c|c|c|c|}
\hline Isoform & $\mathrm{cN}-\mathrm{I}$ & & cN-II & $\mathrm{cN}-\mathrm{III}$ \\
\hline Gene loci products & $\mathrm{cN}-\mathrm{IA}$ & $\mathrm{cN}-\mathrm{IB}$ & & \\
\hline $\begin{array}{l}\text { Nucleotides preferentially } \\
\text { hydrolyzed }\end{array}$ & $\begin{array}{l}\text { AMP } \\
\text { dCMP, dUMP, } \\
\text { dTMP }\end{array}$ & AMP & $\begin{array}{l}\text { IMP, dIMP, GMP, dGMP, } \\
\text { XMP }\end{array}$ & $\begin{array}{l}\text { CMP, UMP, dUMP, } \\
\text { dCMP, dTMP }\end{array}$ \\
\hline $\begin{array}{l}\text { Ability to transfer phosphate } \\
\text { to other nucleoside }\end{array}$ & no & not determined & yes & yes \\
\hline Activators & $\begin{array}{l}\text { ADP, GTP, } \\
\text { dNDP }\end{array}$ & ADP & $\begin{array}{l}\text { dATP, ATP, GTP, ADP, } \\
\text { Ap4A, 2,3-bisphosphogly- } \\
\text { cerate }\end{array}$ & not known \\
\hline $\mathrm{Mg}^{2+}$ dependence & $K_{\mathrm{a}} 3.5-10 \mathrm{mM}$ & & $K_{\mathrm{a}} \quad 100-200 \mathrm{mM}$ & yes \\
\hline Highly expressed in & $\begin{array}{l}\text { skeletal muscle, } \\
\text { heart, brain }\end{array}$ & testis & $\begin{array}{l}\text { pancreas, skeletal muscle, } \\
\text { heart }\end{array}$ & $\begin{array}{l}\text { erythrocytes, lymphoid } \\
\text { cells }\end{array}$ \\
\hline Selective inhibitors & $\begin{array}{l}\text { 5-ethynyl-dide- } \\
\text { oxyuridine }\end{array}$ & not known & $\begin{array}{l}\text { 5'-deoxyisobuthylthio-ade- } \\
\text { nosine (IBTA) }\end{array}$ & not known \\
\hline Enzyme deficiency & not known & not known & not known & hemolytic anemia \\
\hline
\end{tabular}


Other members of the cN-I family were cloned from mouse and human. Unlikely the pigeon, both organisms have two isoforms of cN-I. The human gene coding for cN-IA is located on chromosome 1 , in the region $1 \mathrm{p} 34.3-\mathrm{p} 33$. It comprises six exons and gives rise to a protein of 369 amino acids. No alternative splicing products have been observed for this gene. The other gene coding for $\mathrm{CN}-\mathrm{IB}$ is located on chromosome 2 and it maps to the region $2 \mathrm{p} 24.2$. The protein product of this gene is 550 amino acids long. A comparison of the sequences of those two genes reveals that $\mathrm{cN}-\mathrm{IB}$ includes an additional exon, which adds 181 amino acids to the N-terminus of the protein. Both cN-Iencoding alleles contain the so-called "5-nucleotidase signature" composed of an ATP-binding motif and a $\mathrm{Mg}^{2+}$-binding site. All intracellular nucleotidases including also the $3^{\prime}, 5^{\prime}$-specific variant cdN and the mitochondrial variant mdN (Rinaldo-Matthis et al., 2002) contain three common motifs: I, II, III, being conserved catalytic sequences and $\mathrm{S}$ motif involved in substrate recognition.

\section{PURINE STRUCTURAL ANALOGS AS INHIBITORS AND SUBSTRATES OF VARIOUS $5^{\prime}$-NUCLEOTIDASES}

It is almost canonical that high and stable ATP level ensures survival of the cell. On the other hand, adenosine coming from degradation of ATP has numerous positive effects on tissues. As cN-II has been found as a rate-limiting enzyme in ATP degradation, many studies used cN-II inhibitors to check how it influences the whole adenine nucleotide metabolism. Nucleoside analogs based on thioalkylation of the $5^{\prime}$-position in the ribose moiety in adenosine and inosine able to block the activity of cN-II and to some extent cN-I have been described earlier (Meghji et al., 1993; Skladanowski et al., 1998). Later, the cN-I selective compound - 5-ethynyl-2', $3^{\prime}$-dideoxyuridine inhibiting the hydrolysis of AMP to adenosine in a concentrationdependent manner with an $\mathrm{IC}_{50}$ value of $20 \mu \mathrm{M}$ was reported (Garvey \& Prus, 1999). These studies were performed, however, only in vitro. ADP analog, AOPCP $(\alpha, \beta$-methylene-adenosine diphosphate), has been frequently used to block ecto-5'nucleotidase when studying its role in organ physiology. When AOPCP was infused to the whole animal heart, the effect of a lowered adenosine level on ischemic preconditioning was visible (Kitakaze et al., 1994). Other e5'-NT inhibitors like pentoxifillin or 6-thiopurine enhanced the protective action of cardioplegic fluid during full ischemia (Bolling et al., 1992). The differences in the substrate binding site in cN-I and cN-II were studied and a cru- cial role of the dipole moment of the base in substrate analogs was reported (Skladanowski et al., 1996). These studies might have significance when the role of various cytoplasmic $5^{\prime}$-nucleotidases is considered in the metabolism of anti-cancer and anti-viral nucleoside analogs (for a review see Hunsucker et al., 2005). The nucleotide forms of those analogs were found to be deactivated back to the corresponding nucleoside by cytoplasmic $5^{\prime}$-nucleotidases. On the other hand, cN-II has been shown to introduce a phosphate moiety to nucleoside prodrugs like deoxycoformycin forming then an active drug (Pesi et al., 1994).

\section{CLINICAL RELEVANCE OF CYTOPLASMIC 5'- NUCLEOTIDASES}

The great variety of actions of adenosine emphasizes the importance of the enzymes involved in its production. The only described genetic disorder related to 5'-nucleotidase deficiency, hereditary hemolytic anemia, is caused by a mutation in erythrocyte-specific cN-III. Elevated levels of cN-II have been found in neurological defects and in patients with Lesh-Nyhan syndrome (Pesi et al., 2000; Allegrini et al., 2001). Several studies have shown increased levels of cN-II mRNA in some cancers such as acute myeloid leukemia that correlated with more aggressive leukemic phenotype and poor clinical outcome due to resistance to cytarabine therapy (Galmarini et al., 2001).

In the past decades, investigations were focused mostly on cN-IA and its role in hypoxia and ischemia. Nowadays the clinical potential of soluble 5 '-nucleotidases has been linked to the resistance to anti-cancer and anti-viral drugs basing on their ability to metabolize several analogue monophosphates. Up to date, $\mathrm{cN}-\mathrm{II}$ has been studied the most extensively in this aspect with the most promising results both in vivo and in vitro. The drug resistance was found to be closely related to the level of the enzyme in various cell lines and with different analogues. There is some evidence that the increased levels of cN-II are accompanied by a decrease in $\mathrm{dCK}$ and therefore the ratio of both enzymes might be an important determining factor whether the cell would respond positively to the therapy. Creating a compound that could modulate this ratio could be beneficial for the therapy (Hunsucker et al., 2005).

The family of soluble 5'-nucleotidases seems to have an increasing clinical potential, but there is still much investigation to be done before specific $5^{\prime}$-NT variants of relevance are identified. Development of their inhibitors or compounds that would either overcome the drug resistance or be poorer substrates could move the research forward. 


\section{TRANSPORT OF ADENOSINE VIA CELL MEMBRANE}

Adenosine can cross the cell membrane through influx or efflux. Like other purine or pyrimidine nucleosides, it is transported by systems classified into two classes: equilibrative and concentrative. Adenosine transport during the influx has been more thoroughly studied and now it is well established that targeting the transporter protein by inhibitors (also drugs) has a consequence in the elevation of the extracellular concentration of adenosine required for the activation of P1-type receptors (Paterson et al., 1977; Klabunde, 1983; Zhang \& Lautt, 1991). This might be of pharmacological importance when adenosine is formed extracellularly. During intracellular adenosine formation and subsequent release from the cells, inhibition of the equilibrative transport system can elevate the cytosolic concentration of the metabolite. In such a case, counteracting nucleoside escape, for example during ischemia or washout during reperfusion, may be beneficial for regeneration of the nucleotide pool after a period of ATP breakdown. It has also been suggested that inhibitors of nucleoside transport may decrease the loss of chemotherapeutically active nucleoside-based drugs from the cells. For example, millimolar concentrations of dipyridamole prevented excretion of inosine from $\mathrm{T}$ cell mutants overproducing purine nucleosides (Ullman \& Kaur, 1983). Regulation of adenosine transport in mammalian heart during periods of ischemia or hypoxia have been considered as an important modulator of the heart function strongly dependent on the level of this metabolite. Nucleoside transporters are also under tight regulation by various metabolic and physiological factors (for a review see Podgorska et al., 2005).

\section{CONCLUDING REMARKS}

The aim of this review was to highlight the signaling role of adenosine, a molecule formed by ATP metabolism. Several adenosine effects attract the attention of clinicians. In the heart, adenosine acts as a feed-back regulator of ATP metabolism and provides the fine tuning of the balance between ATP production and utilization. In addition it can convey also a cytoprotective effect against oxidative stress. Clinical studies proved that it might have some beneficial role during coronary reperfusion therapy and minimize the ischemia/reperfusion injury. Activated adenosine receptors in CNS and peripheral tissues have been found as part of a mechanism for modulation of pain transmission. The role in skeletal muscles has not been elaborated yet in details but there are some proofs that a substantial amount produced in this tissue may have an impact on other tissues in the body.

There is a variety of enzymes which can be responsible for adenosine production. Apart from SAHH of little activity and connected to the transmethylation pathway, there are AMP hydrolases or ADP apyrases linked to ATP degradation. They are ubiquitously localized inside and outside the cell. Both adenosine producing enzymes, nucleoside membrane transporters and adenosine receptors offer themselves as molecular targets for developing a whole range of pharmaceutical agents as receptor ligands, modulators or enzyme inhibitors.

The simplest conclusion is that after more than 50 years of studies on adenosine and its mechanisms of action we still have more questions than answers. This makes adenosine related research still exciting and promising to the clinical field.

\section{Acknowledgements}

We thank Professor Wiesław Makarewicz for critical reading of the manuscript.

\section{REFERENCES}

Allegrini S, Scaloni A, Ferrara L, Pesi R, Pinna P, Sgarrella F, Camici M, Eriksson S, Tozzi MG (2001) Bovine cytosolic 5'-nucleotidase acts through the formation of an aspartate 52-phosphoenzyme intermediate. J Biol Chem 276: 33526-33532.

Amici A, Magni G (2002) Human erythrocyte pyrimidine 5'-nucleotidase, PN-I. Arch Biochem Biophys 397: 184190.

Amici A, Emanuelly M, Raffaelly N, Ruggieri S, Saccucci F, Magni G (2000) Human erythrocyte pyrimidine 5'nucleotidase, PN-I, is identical to p36, a protein associated to lupus inclusion formation in response to $\alpha$-interferon. Blood 96: 1596-1598.

Ballard HJ (1991) The influence of lactic acid on adenosine release from skeletal muscle in anaesthetized dogs. $J$ Physiol 433: 95-108.

Ballardinelli L, Linden J, Berne RM (1989) The cardiac effects of adenosine. Prog Cardiovasc 32: 73-97.

Berne RM, Knabb RM, Ely SW, Rubio R (1983) Adenosine in the local regulation of blood flow: a brief overview. Fed Proc 42: 3136-3142.

Bianchi V, Spychala J (2003) Mammalian 5'-nucleotidase. J Biol Chem 278: 46195-46198.

Bianchi V, Pontis E, Reichard P (1986) Interrelations between substrate cycles and de novo synthesis of pyrimidine deoxyribonucleoside triphosphates in 3T6 cells. Proc Natl Acad Sci USA 83: 986-990.

Bolling SF, Childs KF, Ning XH (1992) Amino acid substrate preloading and postischemic myocardial recovery. J Surg Res 53: 324-328.

Bryan PT, Marshall JM (1999a) Adenosine receptor subtypes and vasodilatation in rat skeletal muscle during systemic hypoxia: a role of $\mathrm{A}_{1}$ receptors. J Physiol 514: 151-162.

Bryan PT, Marshall JM (1999b) Cellular mechanism by which adenosine induces vasodilatation in rat skeletal 
muscle: significance for systemic hypoxia. J Physiol 514: 163-175.

Cheng B, Essackjee HC, Ballard HJ (2000) Evidence of control of adenosine metabolism in rat oxidative skeletal muscle by changes in $\mathrm{pH}$. J Physiol 522: 467-477.

Cronstein BN (1994) Adenosine, an endogenous anti-inflammatory agent. J Appl Physiol 76: 5-13.

Cross HR, Murphy E, Black RG, Auchampach J, Steenbergen $C$ (2002) Overexpression of $A_{3}$ adenosine receptors decreases heart rate, preserves energetics and protects ischemic hearts. Am J Physiol 283: H1562-H1568.

Darvish A, Metting P (1993) Purification and regulation of AMP-specific cytosolic 5'-nucleotidase from dog heart. Am J Physiol 264: H1528-H1534.

Darvish A, Pomerantz RW, Zografides PG, Metting PJ (1996) Contribution of cytosolic and membrane-bound 5 '-nucleotidase to cardiac adenosine production. Am J Physiol 271: H21162-H21167.

Deussen A, Mose G, Schrader J (1986) Contribution of coronary endothelial cells to cardiac adenosine production. Pflugers Arch 406: 608-614.

Dobson JG, Rubio R, Berne RM (1971) Role of adenine nucleotides, adenosine and inorganic phosphate in the regulation skeletal muscle blood flow. Circ Res 29: 375-384.

Downey JM, Forman MB (1993) Spotlight on the cardioprotective properties of adenosine. Cardiovas Res 27: 2-140.

Drury AN, Szent-Györgyi A (1929) The physiological activity of adenine compounds with especial reference to their action upon the mammalian heart. J Physiol 68: 213-237.

Dunwiddie TV, Haas HL (1985) Adenosine increases synaptic facilitation in the in vitro rat hippocampus: evidence for a presynaptic site of action. J Physiol 369: 365-377.

Ely SW, Berne RM (1992) Protective effects of adenosine in myocardial ischemia. Circulation 85: 893-904.

Fredholm BB (2003) Adenosine receptors as targets for drug development. Drug News Perspect 16: 283-289.

Fredholm BB, Arslan G, Halldner L, Schulte G, Wasserman W (2000) Structure and function of adenosine receptors and their genes. Naunyn Schmiedeberg's Arch Pharmacol 362: 364-374.

Fredholm BB, Ijzerman AP, Jacobson KA, Klotz KN, Linden J (2001) International Union of Pharmacology. XXV. Nomenclature and classification of adenosine receptors. Pharmacol Rev 53: 527-552.

Galmarini CM, Graham K, Thomas X, Calvo F, Rousselot P, El Jafaari A, Cros E., Mackey JR, Dumontet C (2001). Expression of high $K_{\mathrm{m}}$-nucleotidase in leukemic blasts is an independent prognostic factor in adults with acute myeloid leukemia. Blood 98: 1922-1926.

Garvey EP, Prus KL (1999) A specific inhibitor of heart cytosolic 5'-nucleotidase I attenuates hydrolysis of adenosine $5^{\prime}$-monophosphate in primary rat myocytes. Arch Biochem Biophys 364: 235-240.

Garvey EP, Lowen GT, Almond MR (1998) Nucleotide and nucleoside analogues as inhibitors of cytosolic 5'-nucleotidase I. Biochemistry 37: 9043-9051.

Gazziola C, Ferraro P, Moras M, Reichard P, Bianchi V (2001) Cytosolic high $K_{\mathrm{m}} 5^{\prime}$-nucleotidase and 5'(3')-deoxyribonucleotidase in substrate cycles involved in nucleotide metabolism. J Biol Chem 276: 6185-6190.

Han D-H, Hansen PA, Nolte LA, Holloszy JO (1998) Removal of adenosine decreases the responsiveness of muscle glucose transport to insulin and contraction. Diabetes 47: 1671-1675.
Hellsten Y (1999) The effect of muscle contraction on the regulation of adenosine formation in rat skeletal muscle cells. J Physiol 518: 761-768.

Hellsten Y, Frandsen U (1997) Adenosine formation in contracting primary skeletal muscle cells and endothelial cells in culture. J Physiol 504: 695-704.

Hunsucker SA, Spychala J, Mitchell BS (2001) Human cytosolic 5'-nucleotidase: characterization and role in nucleoside analog resistance. J Biol Chem 276: 10498-10504.

Hunsucker SA, Mitchell BS, Spychala J (2005) The 5'-nucleotidases as regulators of nucleotide and drug metabolism. Pharmacol Ther 107: 1-30.

Imai S, Nakazawa M, eds (1991) Role of Adenosine and Adenine Nucleotides in the Biological System. Metabolism, Release, Transport, Receptors, Transduction Mechanism and Biological Actions, p 726, Elsevier, Amsterdam.

Itoh R (1993) IMP-GMP 5'-nucleotidase. Comp Biochem Physiol B 105: 13-19.

Jacobson KA, Hoffmann C, Cattabeni F, Abbracchio MP (1999) Adenosine-induced cell death: evidence for receptor-mediated signaling. Apoptosis 4: 197-211.

Kitakaze M, Hori M, Minamino T, Takashima S, Komamura $K$, Node $K$, Kurihara T, Morioka T, Sato $H$, Inoue M, Kamada T (1994) Evidence for deactivation of both ectosolic and cytosolic $5^{\prime}$-nucleotidase by adenosine $\mathrm{A}_{1}$ receptor activation in the rat cardiomyocytes. J Clin Invest 94: 2451-2456.

Klabunde RE (1983) Dipyridamole inhibition of adenosine metabolism in human blood. Eur J Pharmacol 93: 21-26.

Lu Y, LI Y, Herin GA, Aizenman E, Epstein PM, Rosenberg PA (2004) Elevation of intracellular cAMP evokes activity-dependent release of adenosine in cultured rat forebrain neurons. Eur J Neurosci 19: 2669-2681.

Meghji P, Skladanowski AC, Newby AC, Slakey LL, Pearson JD (1993) Effect of 5'-deoxy-5'-isobutylthioadenosine on formation and release of adenosine from neonatal and adult rat ventricular myocytes. Biochem J 291: 833-839.

Newby AC (1984) Adenosine and the concept of "retaliatory metabolites". Trends Biochem Sci 9: 42-44.

Newby AC (1988) The pigeon heart 5'-nucleotidase responsible for ischemia-induced adenosine formation. Biochem J 253: 123-130.

Obata T (2002) Adenosine production and its interaction with protection of ischemic and reperfusion injury of myocardium. Life Sci 71: 2083-2103.

Oka J, Matsumoto A, Hosokawa Y, Inoue S (1994) Molecular cloning of human cytosolic purine 5'-nucleotidase. Biochem Biophys Res Commun 205: 917-922.

Page T, Yu A, Fontanesi J, Nyhan WL (1997) Developmental disorder associated with increased cellular nucleotidase activity. Proc Natl Acad Sci USA 94: 11601-11606.

Paterson AR, Babb LR, Paran JH, Cass CE (1977) Inhibition by nitrobenzylthioinosine of adenosine uptake by asynchronous HeLa cells. Mol Pharmacol 13: 1147-1158.

Pesi R, Turriani M, Allegrini S, Scolozzi C, Camici M, Ipata PL, Tozzi MG (1994) The bifunctional cytosolic 5'nucleotidase: regulation of the phosphotransferase and nucleotidase activities. Arch Biochem Biophys 312: 75-80.

Pesi R, Micheli V, Jacomelli G, Peruzzi L, Camici M, Garcia-Gil M, Allegrini S, Tozzi MG (2000) Cytosolic 5'nucleotidase hyperactivity in erythrocytes of Lesch-Nyhan syndrome patients. Neuroreport 11: 1827-1831.

Podgorska M, Kocbuch K, Pawełczyk T (2005) Recent advances in studies on biochemical and structural properties of equilibrative and concentrative nucleoside transporters. Acta Biochim Polon 52: 749-758. 
Radegran A, Hellsten Y (2000) Adenosine and nitric oxide in exercise-induced human skeletal muscle vasodilatation. Acta Physiol Scand 168: 575-579.

Rees DC, Duley JA, Marinaki AM (2003) Pyrimidine 5' nucleotidase deficiency. Br J Haematol 120: 375-383.

Relavic V, Burnstock G (1998) Receptors for purines and pyrimidines. Pharmacol Rev 50: 413-480.

Rinaldo-Matthis A, Rampazzo C, Reichard P, Bianchi V, Nordlund P (2002) Crystal structure of a human mitochondrial deoxyribonucleotidase. Nat Struct Biol 9: 779-787.

Rubio R, Berne RM, Dobson JG Jr (1973) Sites of adenosine production in cardiac and skeletal muscle. Am J Physiol 255: 938-953.

Sala-Newby GB, Newby AC (2001) Cloning of a mouse cytosolic $5^{\prime}$-nucleotidase-I identifies a new gene related to human autoimmune infertility-related protein. Biochem Biophys Acta 152: 12-18.

Sala-Newby GB, Skladanowski AC, Newby AC (1999) The mechanism of adenosine formation in cells. Cloning of cytosolic 5'-nucleotidase I. J Biol Chem 274: 1778917793.

Sala-Newby GB, Freeman NV, Skladanowski AC, Newby AC (2000) Distinct roles for recombinant cytosolic 5'nucleotidase-I and -II in AMP and IMP catabolism in COS-7 and H9c2 rat myoblast cell lines. J Biol Chem 275: 11666-11671.

Sawynok J, Sweeney MJ (1989) The role of purines in nociception. Neuroscience 32: 557-569.

Shryock JC, Belardinelli LB (1997) Adenosine and adenosine receptors in the cardiovascular system: biochemistry, physiology and pharmacology. Am J Cardiol 79: 2-10.

Silinsky EM (1975) On the association between transmitter secretion and the release of adenine nucleotides from mammalian motor nerve terminals. J Physiol 247: 145162.

Skladanowski AC, Newby AC (1990) Partial purification and properties of an AMP-specific soluble $5^{\prime}$-nucleotidase from pigeon heart. Biochem J 268: 117-122.

Skladanowski AC, Smolenski RT, Tavernier M, De Jong JW, Yacoub MH, Seymour AM (1996) Soluble forms of 5'-nucleotidase in rat and human heart. Am J Physiol 210: H1493-H1500.

Skladanowski AC, Newby AC, Makarewicz W (1998) Purification and some molecular properties of pigeon heart AMP-selective 5'-nucleotidase. Adv Exp Med Biol 431: 113-117.

Spychala J (2000) Tumor-promoting functions of adenosine. Pharmacol Ther 87: 161-173.

Spychala J, Mitchell BS, Barankiewicz J (1997) Adenosine metabolism during phorbol myristate acetate-mediated induction of HL-60 cell differentiation: changes in expression pattern of adenosine kinase, adenosine deaminase and 5'-nucleotidase. J Immunol 158: 4947-4952.

Thorn JA, Jarvis SM (1996) Adenosine transporters. Gen Pharmacol 27: 613-620.

Tkacz-Stachowska K, Lechward K, Skladanowski AC (2005) Isolation and characterization of pigeon breast muscle cytosolic 5'-nucleotidase-I (cN-I). Acta Biochim Polon 52: 789-796.

Truong VL, Collinson AR, Lowenstein JM (1988) 5'-Nucleotidases in rat heart. Evidence for occurrence of two soluble enzymes with different substrate specificities. Biochem J 253: 117-121.

Ullman B, Kaur K (1983) Biochemical effects of dipyridamole on purine overproduction and excretion by mutant murine T-lymphoblasts. J Biol Chem 258: 9620-9622.

Yaar R, Jones MR, Chen JF, Ravid K (2005) Animal models for the study of adenosine receptor function. J Cell Physiol 202: 9-20.

Yamazaki Y, Truong VL, Lowenstein JM (1991) 5'-Nucleotidase I from rabbit heart. Biochemistry 3: 1503-1509.

Zhang Y, Lautt WW (1991) Dilazep increases plasma adenosine levels during adenosine infusion in the anesthetized cat. Proc West Pharmacol Soc 34: 167-169.

Zimmermann H (1994) Signaling via ATP in the nervous system. Trends Neurosci 17: 420-426.

Zimmermann H, Braun N (1996) Extracellular metabolism of nucleotides in the nervous system. J Autonom Pharmacol 16: 397-400. 